\title{
Study on Spatial Econometrics of Level Spatial Data of Knowledge Spillover Effect in Industrial Industry in Guangdong Province
}

\author{
Yao Wang \\ School of Business Administration, South China University of Technology, Guangzhou, China \\ Email: 13570310449@163.com
}

How to cite this paper: Wang, Y. (2018) Study on Spatial Econometrics of Level Spatial Data of Knowledge Spillover Effect in Industrial Industry in Guangdong Province. Open Journal of Business and Management, 6, 568-575.

https://doi.org/10.4236/ojbm.2018.63043

Received: April 17, 2018

Accepted: June 4, 2018

Published: June 7, 2018

Copyright $\odot 2018$ by author and Scientific Research Publishing Inc. This work is licensed under the Creative Commons Attribution International License (CC BY 4.0).

http://creativecommons.org/licenses/by/4.0/

\begin{abstract}
This paper uses an econometric model of hierarchical data space to do empirical research on the knowledge spillover effect of industrial industries in Guangdong Province. Specifically, three-dimensional panel data (regions, industries, and time) of 21 prefecture-level cities and 31 industrial industries in Guangdong Province from 2005 to 2016 were used and spatial correlation, time factors, and hierarchical nesting effects were taken into consideration to establish hierarchical data. The spatial econometric model uses an industrial structure to empirically analyze the impact of the knowledge spillover effect of the industrial industry in Guangdong on its economic development.
\end{abstract}

\section{Keywords}

Knowledge Spillover, Hierarchical Data, Industrial Structure

\section{Introduction}

It has been a topic of debate both at home and abroad for the knowledge of what kind of industrial structure knowledge spillover has had a significant impact on the development of industrial industries. There are three main viewpoints: MAR knowledge spillovers believe that knowledge mainly comes from companies in the same industry, and is specialized in industrial structure. It can promote the creation and dissemination of knowledge and thus promote the growth of the industrial economy; and Jacobs knowledge spillovers believe that knowledge mainly comes from companies in different industries. The more diversified the industrial structure is, the more conducive to economic growth; Porter knowledge spillover believes that the highly competitive industrial environment will help encourage the company to continue to innovate, and the monopoly is un- 
favorable to knowledge innovation and economic growth.

The above three types of knowledge spillovers are theoretical ones. How the industrial structure influences knowledge spillovers and whether knowledge technology promotes economic development need to be judged through empirical research. Scholars from different countries use empirical data from different regions, different industrial industries, and different time periods to conduct empirical analysis of knowledge spillover effects. Among them, the literature on the Chinese industrial industry is Mody and Wang, 1997 [1], Ce'cile BATISSE, 2002 [2], Zhang and WU, 2008 [3], Cai Jie (2006) [4], Zhang Wei (2007) [5], Duan Huijuan (2009) [6], and the literature on Guangdong's industrial industry only Wu Mei (2012) [7], Liu Xipeng (2015) [8].

Empirical studies on knowledge spillovers at home and abroad explore the impact of knowledge spillovers in different countries and regions on employment, economic growth, patents, etc. The conclusions are not consistent. There are two groundbreaking papers on the empirical study of the role of knowledge spillover in industrial development. First, Glaeseretal (1992) [9] studied the paper on the impact of knowledge spillovers on economic development. This paper used panel data of 8 industries distributed in 224 regions of the United States from 1970 to 1987, with the logarithmic growth rate of employment and logarithmic growth rate of wages as dependent variables. The study finds that the main source of knowledge spillovers is not the same between industries, but between different industries. Henderson et al. (1995) [10] and others further studied this panel data and found that different conclusions from Glaeseretal: different industries have different knowledge spillover characteristics, high-tech industry coexistence of obvious Porter spillover and MAR spillover. But the MAR spillover effect exists only in the traditional industrial industry. Friso de Vor.Henri LF de Groot (2008) [11] established a linear model and studied the externalities and local employment growth of the industrial sector in Amsterdam (Netherlands) from 1998 to 2006 and found that despite the Jacobs spillover effect and the Porter spillover effect, both are weak, but MAR spillover has a significant negative effect. Shan Lingyu (2010) [12] studied the relationship between knowledge spillover effects and spatial autocorrelation in spatial location based on data from 32 provincial-level industrial developments in the country, and found that Porter spillover effects and Jacobs spillover effects in provincial unit industries. All are obvious, but the MAR spillover effect is weak. Ning Junming (2008) [13] selected 27 industrial industries in 31 provinces in China to analyze the relationship between China's economic growth and knowledge spillovers, and found that the characteristics of a single industry in the region are specialized, and the characteristics of the overall region are diverse. It also shows that the MAR spillover effect and the Jacobs spillover effect are not antagonistic. Liu Manfeng and Wu Zhuoxian (2013) [14] collected high-tech industrial cluster data from 2008 to 2010 to establish a double-logarithmic spatial econometric model, studied the knowledge spillover effect of high-tech industries, and found that the MAR effect and Jacobs effect are prominent in China. 
Taking a look at similar studies at home and abroad, most of them use data from different countries in different periods to establish a two-dimensional panel data model to study knowledge spillover effects. Three aspects of such research need to be further improved: First, no spatial correlation is considered, second, the correlation in the time dimension is not considered, and third, the hierarchical nesting effect is not considered. In view of these three types of issues, this paper adopts a hierarchical data space econometric model to empirically study the impact of knowledge spillovers in high value-added industrial industries in Guangdong on economic growth.

\section{Model and Econometric}

\subsection{Empirical Theoretical Model}

The production function method is usually based on the Cobb-Douglas (C-D) basic production function. Through the regression analysis of economic growth on capital, labor, and technology, the effect of knowledge spillover on economic growth is described. C-D basic production function:

$$
Y_{i j t}=A_{i j t} L_{i j t}^{\alpha} K_{i j t}^{\beta}
$$

In the formula, $i$ denotes the region, $j$ denotes the industry, and $t$ denotes the time. $A$ denotes technical level, $L$ denotes labor input, $K$ denotes capital input, $Y$ denotes industrial added value, and represents economic growth.

Since the relationship between the output of formula (1) and the three inputs is nonlinear, the logarithmic transformation of both sides of the function can yield the following model:

$$
\ln Y_{i j t}=\alpha \ln L_{i j t}+\beta \ln K_{i j t}+\gamma \ln A_{i j t}+\varepsilon_{i j t}
$$

By splitting the technical level $A$ in formula (2), the functional relationship between technical level $A$ and specialization (SPEC), diversification (DIV), and competitiveness (COMP) indicators can be obtained. The function is as follows:

$$
A=f(S P E C, D I V, C O M P)+\varepsilon
$$

In the empirical study, the specialization, diversity and competitive indicator are set as the following calculation formula:

$$
\begin{aligned}
& \operatorname{SPEC}(V A)_{i j t}=\frac{V A_{i j t} / V A_{i t}}{V A_{j t} / V A_{t}} \\
& D I V(V A)_{i j t}=\frac{1 / \sum_{j^{\prime} \neq j}^{J}\left(\frac{V A_{i j^{\prime} t}}{V A_{i t}-V A_{i j t}}\right)^{2}}{1 / \sum_{j^{\prime} \neq j}^{J}\left(\frac{V A_{j^{\prime} t}}{V A_{t}-V A_{j t}}\right)^{2}} \\
& \operatorname{COMP}(V A)_{i j t}=\frac{N_{i j t} / V A_{i j t}}{N_{j t} / V A_{j t}}
\end{aligned}
$$

In the formula, $V A$ represents the industrial added value, and $N$ represents 
the number of employees.

An empirical analysis theoretical model of knowledge spillovers can be obtained:

$$
\ln Y_{i j t}=\alpha \ln L_{i j t}+\beta \ln K_{i j t}+\gamma_{1} S P E C_{i j t}+\gamma_{2} D I V_{i j t}+\gamma_{3} C O M P_{i j t}+\varepsilon_{i j t}
$$

In this paper, the model (7) is estimated using a hierarchical data space econometric model.

\subsection{Econometric Model}

At the same time, we consider the nested relationship between the research object hierarchy and the spatial error correlation of the hierarchical structure data model. For the three-level data structure, we establish a hierarchical spatial error autoregressive model (HSEAR). The function is as follows:

$$
\begin{gathered}
y_{i j t}=x_{i j t} \beta+u_{i j t} \\
u_{i j t}=\rho \sum_{g=1}^{N} \sum_{h=1}^{m_{g}} w_{i j, g h} u_{g h t}+\varepsilon_{i j t} \\
\varepsilon_{i j t}=\alpha_{i}+\mu_{i j}+v_{i j t}
\end{gathered}
$$

In order to obtain asymptotically effective GMM estimators, we use the variance covariance matrix of the moment conditions to construct the optimal weight matrix. The results of the optimal weight matrix derivation are as follows:

$$
\Xi=\left[\begin{array}{cc}
\frac{\xi_{1}^{2}}{T-1} T_{1} & 0 \\
0 & T_{2}
\end{array}\right]
$$

The basic idea of the GMM estimation is to minimize the weighted distance between the sample moments, that is, to minimize the following objective function, the optimal weight GMM estimator is defined as:

$$
\begin{aligned}
& \left(\hat{\rho}, \widehat{\xi}_{1}, \widehat{\xi}_{2}, \widehat{\sigma_{\alpha}^{2}}\right) \\
& =\arg \min \left\{\begin{array}{l}
\varsigma\left(\rho, \xi_{1}, \xi_{2}, \sigma_{\alpha}^{2}\right)^{\mathrm{T}} \Xi^{-1} \varsigma\left(\rho, \xi_{1}, \xi_{2}, \sigma_{\alpha}^{2}\right) \\
\rho \in[-a, a], \xi_{1} \in[0, b], \xi_{2} \in[0, c], \sigma_{\alpha}^{2} \in\left[0, \frac{1}{T m_{i}}(d-c)\right]
\end{array}\right.
\end{aligned}
$$

\section{Results and Analyses}

This study used three-dimensional panel data from 21 regions and 31 industries in Guangdong Province from 2005 to 2016 to conduct empirical research on the knowledge spillover effect of Guangdong's industrial industries. The index system should refer to 2.1. This study can obtain data on variables such as industrial added value, number of companies, number of employees, capital, etc. The data were derived from the "Guangdong Industrial Economic Statistical Yearbook" in various years. Considering the nesting effect among data levels, an autoregressive model of spatial data error is established. The GMM estimator is used to estimate the standard deviation of the error term, and then the FGLS of the overall 
regression parameters is estimated the effect of empirical analysis. The results of the econometric model of hierarchical data space are shown in "Table 1". The results of nested random effects are shown in "Table 2".

As can be seen from Table 1, because of $P$ value $<0.0001$, the spatial correlation coefficient SPAR estimate is completely significant, indicating that there is a clear spatial correlation. From the results of $P$ value, $T$ value and standard error, all the explanatory variables pass the test with significance level of $0.1 \%$, indicating that the introduction of hierarchical nesting effect makes the coefficient estimation effect is better.

From Table 2, it can be seen that the standard deviation of regional level random effects for measuring the degree of regional differences is $\sigma_{\alpha_{i}}=0.17512$; considering the industry being nested in the region, the standard deviation of random effects of industry nesting for measuring the degree of difference between industries is $\sigma_{u_{i j}}=0.38415$, indicating that the extent of regional random effects and the degree of nested random effects differences can be identified. Therefore, the empirical results obtained using the hierarchical spatial error autoregressive model which considers the local correlation of spatial errors, the correlation of temporal factors, and nested random effects are closer to the economic reality.

Judging from the estimation results, the estimates of the specialization spillover coefficient $\left(\gamma_{1}\right)$ and the diversification (DIV) coefficient of spillover effect $\left(\gamma_{2}\right)$ are both significantly positive, indicating the specialization and diversification of the industrial structure to the Guangdong Province. The development of the industrial industry has had a significant positive effect. Among them, the estimated value of diversification (DIV) spillover effect coefficient $\left(\gamma_{2}\right)$ is much larger than the estimated values of the other two coefficients, indicating that the knowledge spillovers of the industrial industry in Guangdong Province not only exist in the same industry, but also exist in different industries and geographical

Table 1. Hierarchical data space econometric model estimation results.

\begin{tabular}{ccccc}
\hline & Coefficient estimate & Standard error & $T$ value & $P$ value \\
\hline SPAR & 0.2854 & 0.0032 & 15.47 & $2.4 \mathrm{e}-021$ \\
$\alpha$ & 0.3134 & 0.0021 & 55.37 & $3.4 \mathrm{e}-104$ \\
$\beta$ & 0.5986 & 0.0011 & 83.19 & 0.00000 \\
$\gamma_{1}$ & 0.0542 & 0.0035 & 9.96 & $3.7 \mathrm{e}-013$ \\
$\gamma_{2}$ & 0.4127 & 0.0037 & 5.87 & $1.2 \mathrm{e}-09$ \\
$\gamma_{3}$ & -0.0759 & 0.0022 & -49.55 & $2.2 \mathrm{e}-092$ \\
\hline
\end{tabular}

Table 2. Nested random effects model results.

\begin{tabular}{ll}
\hline$\sigma_{v_{j / t}}$ & 0.49546 \\
\hline$\sigma_{u_{j}}$ & 0.38415 \\
$\sigma_{\alpha_{i}}$ & 0.17512 \\
\hline
\end{tabular}


agglomeration enterprises. The diversity and diversity have promoted the innovation of the enterprise. The innovation of an industry can also bring about the innovation of other industries and form a reciprocal effect on spatial aggregation, thereby promoting the growth of the overall industrial economy. The COMP coefficient of spillover effect $\left(\gamma_{3}\right)$ is significantly negative, indicating that the higher the level of industry monopolization, the more conducive to the dissemination and diffusion of knowledge in different industries within the same industry, thus driving the growth of the industrial economy.

\section{Conclusions}

The results show that the knowledge spillover effect of MAR in Guangdong's industrial industry is significantly positive, indicating that the specialized industrial structure is conducive to the spread and diffusion of knowledge within the same industry, which in turn drives the development of the industrial economy. This is in line with the phenomenon that the industrial clusters in the Guangdong Province have regional economic accumulation and high product market concentration as well as the phenomenon of "one village one product, one town and one industry". The knowledge spillover effect of Jacobs in Guangdong's industrial industry is significantly positive, indicating that diversified industrial structure is conducive to the spread and diffusion of knowledge among different industries. That is, knowledge spillover exists not only in the same industry but also in different industries. The diversity of geographical agglomeration enterprises promotes the innovation of enterprises. The innovation of an industry can also bring about the innovation of other industries and form a reciprocal effect on spatial aggregation, thereby promoting the growth of the overall industrial economy. The knowledge spillover effect of Porter in Guangdong's industrial industry is significantly negative, indicating that monopolistic rather than competitive industrial structure is conducive to the dissemination and diffusion of knowledge, thereby stimulating the development of the industrial economy. Oligarch monopoly companies have human, material and financial resources to support R \& D activities and are the source of knowledge innovation. In the structure of the oligopoly market, the degree of market concentration is high, and oligopolistic companies often adopt cooperative methods to maintain market position, raise industry entry barriers, and frequently communicate with each other, which is conducive to the spread of knowledge. However, if there is greater competition within the industry, in order to maintain their respective competitiveness, companies will keep their own core technical knowledge strictly confidential and will not carry out too much exchange activities with each other, which is not conducive to the spread of knowledge. This is why Porter's knowledge spillover is negative.

The main contribution of this paper is to consider the hierarchical nesting effect between data. The society is a whole with a hierarchical structure. The data reflecting the operation of the social economy has a multi-level, nested or hie- 
rarchical structure. The lower levels are nested or included in the higher levels and influence each other. The existing studies assume that each level is independent and unrelated, neglecting the nested relationships and interactions between different levels and bringing great differences to the research results. Therefore, introducing a hierarchical nesting effect in the econometric model can more accurately describe the knowledge spillover effect in the development of the industrial industry in Guangdong Province.

In the process of research, because the research objects are related to regions and industries, this paper attempts to consider the factors of industry relevance in the spatial weight matrix. That is, the input-output method is used to calculate the industry correlation coefficient matrix, and then the Kronecker product operation is performed with the geographic weight matrix to obtain a spatial weight matrix. The spatial weight matrix is added to the econometric model of the panel data space. The estimated value obtained is not significant, and the estimation effect is not ideal. Therefore, the spatial weight matrix is abandoned. I think the problem lies mainly in the industrial correlation coefficient matrix. The input-output method is to express the interaction between A and B by outputting 1 unit of A. B. This method can be used to a certain extent, represents the correlation between two industries, but does not have symmetry. That is, how much $B$ needs to be consumed to produce $A$ unit is different from how much $\mathrm{A}$ is consumed to produce 1 unit $\mathrm{B}$. Therefore, finding a suitable method to represent the industry correlation coefficient is the key to solving this problem, and it is also a problem to be solved in the setting of spatial weight matrix.

\section{Acknowledgements}

The authors are grateful for the support of professors from South China University of Technology. We appreciate the constructive comments from Long Zhihe. I also thank Ye Qianting for valuable suggestions on a previous version of the paper.

\section{References}

[1] Mody, A. and Wang, F.Y. (1997) Explaining Industrial Growth in Coastal China: Economic Reforms ... and What Else? World Bank Economic Review, 11, 293-325. https://doi.org/10.1093/wber/11.2.293

[2] Batisse, C. (2002) Dynamic Externalities and Local Growth-A Panel Data Analysis Applied to Chinese Provinces. China Economic Review, 13, 231-251.

[3] Zhang, M.Q. and Wu, Y.L. (2008) Impact of Agglomeration Spill over in Spatial Difference of Innovation Activities-Panel Data Analysis of China Manufacturing Industry. Micro Evidence on Innovation in Developing Economies Conference Papers, 3, 24-35.

[4] Cai, J. and Long, Z.H. (2006) Impact of Knowledge Dynamic Spillovers on Industrial Development: Evidence from Provincial Panel Data in China. Southern Econo$m y, 4,5-14$.

[5] Zhang, H. and Li, L.-S. (2007) Manufacturing Cluster, Knowledge Spillovers, and Regional Innovation Performance: A Case Study of China's Pharmaceutical, Elec- 
tronics and Communications Equipment Manufacturing Industry. Quantitative Economics and Technology Economics Research, 8, 35-89.

[6] Duan, H.J. and Liang, Q. (2009) Local Specialization, Knowledge Spillovers and Regional Innovation Efficiency-Based on the Analysis of China's Provincial Panel Data. Economic Forum, 11, 21-23.

[7] Wu, M. (2012) Empirical Study on the Spatial Econometrics of the Knowledge Spillover Effect in Guangdong's Industrial Industry. South China University of Technology, No. 2, 18-24.

[8] Liu, S.P. (2015) Empirical Study on Knowledge Spillover Effect of Industrial Industry in Guangdong Province: 2005-2013. South China University of Technology, No. 3, 12-22.

[9] Glaeser, E.L., Kallal, H.D., Scheinkman, J.A. and Schleifer, A. (1992) Growth in Cities. Journal of Political Economy, 100, 1126-1152. https://doi.org/10.1086/261856

[10] Henderson, V., Kuncoro, A. and Turner, M. (1995) Industrial Development in Cities. Journal of Political Economy, 103, 1067-1090. https://doi.org/10.1086/262013

[11] Vor, F. and de Groot, H.L.F. (2010) Agglomeration Externalities and Localized Employment Growth: The Performance of Industrial Sites in Amsterdam. Annals of Regional Science, 44, 409-431.

[12] Shan, L.Y. (2010) Research on the Influence of Knowledge Spillover on Manufacturing Development-Based on the Analysis of Spatial Econometrics. Thesis and Dissertation of Nanjing University of Finance and Economics, 21-30.

[13] Ning, J.M. (2008) Economic Structure-Knowledge Spillover and Regional Economic Growth in China. Contemporary Finance and Economics, 4, 14-16.

[14] Liu, M.F. and Wu, Z.X. (2013) An Empirical Study on Mar Effect and Jac Effect of Knowledge Spillover in High-Tech Industrial Clusters. Science, Science Technology Management, 8, 83-92. 